\title{
Machine learning for predictive electrical performance using OCD (Erratum)
}

Sayantan Das, Joey Hung, Sandip Halder, Guillaume Schelcher, Roy Koret, et al.

Sayantan Das, Joey Hung, Sandip Halder, Guillaume Schelcher, Roy Koret, Igor Turovets, Mohamed Saib, Anne-Laure Charley, Matthew J. Sendelbach, Avron Ger, Philippe Leray, "Machine learning for predictive electrical performance using OCD (Erratum)," Proc. SPIE 10959, Metrology, Inspection, and Process Control for Microlithography XXXIII, 1095932 (25 June 2019); doi: $10.1117 / 12.2541616$ 


\section{Mac hine leaming for predic tive electric al performance using OCD (Enatum)}

Sayantan Dasa, J oey Hungb , Sandip Haldera, Roy Koretb, Igor Turovets ${ }^{b}$, Mohamed Sailba, Anne-Laure Charleya, Matthew Sendelbachc, Avron Gerb, and Philippe Leraya

a Imec Kapeldreef 75, B-3001 Leuven, Belgium

b Nova Measuring Instruments, Ltd., P.O. Box 266, Weizmann Sc ience Park, Rehovot 76100, Israel

c Nova Measuring Instruments, Inc., 3090 Oakmead Village Drive, Santa Clara, CA 95051, United States

Proceedings Volume 10959, Metrology, Inspection, and Process Control for Mic rolithography XXXIII; 109590F (2019) https://doi.org/10.1117/12.2515806

Event Advanced Lithography, 2019, San J ose, Califomia, United States

Online Publication Date: 26 Ma rch 2019

Eratum Published: 25 J une 2019

A revised version of this manusc ript was published on $25 \mathrm{~J}$ une 2019. Details of the revision are provided below. The original paper has been updated.

This article "Proceedings Volume 10959, Metrology, Inspection, and Process Control for Microlithography XXXIII; 109590F (2019)" was originally published on 26th March 2019 with an error in the slope value in Figure 9c which has been now been corrected.

As a result, this sentence was modified in the new manuscript:

"It was found that there is a good correlation between the capacitance values calculated using the parameters obtained from the OCD model and the measured capacitance value"

The correction does not affect any qualitative or quantitative results and conclusions. 